the nature of soap emulsions and on the theory of capillarity and colloidal solutions. His theory of membrane equilibrium and membrane potential is an achievement of the first rank, and has been the starting-point of numerous studies not only in the domain of pure chemistry, but more especially in biochemistry, where the conditions for displaying the phenomena he predicted are often encountered. His researches on surface tension and absorption at liquid-liquid interfaces have led to results of the greatest interest, and his verification by means of nonylic acid of the Gibbs' absorption formula is a most brilliant experimental conception. A by-product of his activities during the War is a theory of the action of gasscrubbers, based on the velocity of absorption of gases by liquids.

\section{The Darwin Medal, awarded to Dr. Leonard} COCKAYNE.

A true naturalist, Dr. Cockayne has waited patiently upon facts before drawing conclusions. For more than thirty years he has made it his task to deepen and widen our knowledge of New Zealand botany in the broadest sense. $\mathrm{He}$ is one of the foremost living students of plant-association; the taxonomic studies rendered necessary by his ecological results have led to those remarkable discoveries of natural hybrids in New Zealand that have won for him a world-wide reputation and have made on modern thought an impression akin to that produced by the results of Darwin's studies of plants under domestication. Dr. Cockayne's researches have had, on sylvicultural and agricultural procedure, a practical bearing which has been appreciated by, and has influenced the policy of, New Zealand statesmen.
The Sylvester Medal, awarded to Prof. William Henry Young.

Dr. W. H. Young has taken a very prominent part in the development of the modern theory of functions of real variables, and in its application to the theory of Fourier's and other series. His earlier work dealt ehiefly with the theory of sets of points, and contains important developments on the lines laid down by G. Cantor and Harnack. He soon preceeded to apply this theory in the integral calculus, and he obtained a general definition of the integral which is essentially equivalent to, although somewhat less simple in form, that given about the same time by $H$. Lebesgue, which latter has become a corner stone of modern analysis. Much of Dr. Young's work has proved to be a starting point for further investigations by other mathematicians. By means of his conception of restricted Fourier's series he was enabled to devise a method by which conditions of convergence, summability, etc., known to hold good for Fourier's series, could be carried over to series of Legendre's and Bessel's functions.

\section{The Hughes Medal, awarded to M. Le} DUC DE BROGLIE.

Maurice François César, Duc de Broglie, is distinguished especially for his pioneer researches on $\mathrm{X}$-ray spectra and secondary $\beta$-rays. $H e$ was one of the first to obtain the complete emission spectrum of $\mathrm{X}$-rays and to study $\mathrm{X}$-ray absorption spectra, while his work on the magnetic spectrum of the $\beta$-rays, arising from the passage of $\mathbf{X}$-rays through matter, has proved of great importance. He founded in Paris a private laboratory directed by himself, which is devoted to researches on X-rays and allied subjects.

\title{
Applied Chemistry.
}

\section{Physical Chemistry and Brology.}

THE first Liversidge lecture was delivered before the Chemical Society on Nov. 29 by Prof. F. G. Donnan, who discussed the applications of physical chemistry in the service of biology. In connexion with similar lectures to be provided by the University of Sydney, the Royal Society of New South Wales, and the Australasian Association for the Advancement of Science, this series of annual lectures has been established by the Chemical Society in accordance with the terms of a bequest by the late Prof. Liversidge, of the University of Sydney, a bequest which was made with the object of stimulating thought and encouraging the acquisition of new knowledge. Liversidge lectures delivered before the Chemical Society will be concerned with physical and inorganic chemistry, whilst another series of lectures, perpetuating the memory of the late Sir Alexander Pedler, will deal similarly with organic chemistry.

Prof. Donnan first referred briefly to the part played by organic and inorganic chemistry in the advancement of biology. Physical chemistry, as created by Raoult, van 't Hoff, Ostwald, Arrhenius, and Nernst, first began to exert a powerful influence on biology, although no period in the development of physical chemistry clearly marked the beginning of the application of that science to biological problems. The osmotic theory of semi-permeable membranes, based on the work of Pfeffer and van 't Hoff, was of exceptional importance in its explanation of the then mysterious vital action of the living cell. The triumph and development of the ionic theory has revolutionised a large part of the theory of solutions, and has been of correspondingly fundamental im- portance in the study of essential constituents of the living organism; the hydrogen ion activity determines the molecular state and colloidal condition of the amphoteric proteins in aqueous solution, and the optimum activity of enzymes. It is not surprising, therefore, that the delicate dynamic equilibrium of living protoplasm requires a close regulation of the hydrogen ion concentration, determinable by known or theoretically calculable ionic equilibria.

Prof. Donnan also referred during his discourse to the great biological importance of the thermodynamical studies of Willard Gibbs, to whom we owe very important considerations relating to surfaces of separation between different media. There exist at such surfaces powerful uncompensated fields of atomic and molecular forces, as a result of which molecules and ions are held or adsorbed in spite of general thermal agitation tending to disperse them. Some of the forces may be of considerable extent, and perhaps considerable symmetry, whilst others are highly localised; the latter are of great importance since they cause the orientation and regular arraying of molecules and ions at surfaces and surface films. "A living cell," said Prof. Donnan, " is not merely a little bag containing salts, proteins, sugars, fats, and enzymes in which chemical reactions occur as in a beaker or flask. There is organisation, and organisation in space means arrangement. In this orientation and arraying of molecules and ions at surfaces we may perceive, perhaps, the first faint glimmering of the organised arrangement of life's mechanism."

Finally, Prof. Donnan referred to three considerations of major significance which must be taken into account. First, that the laws of thermodynamics, being statistical in their nature, do not necessarily

No. 3084, VoL. 122] 
apply universally in very small systems. Further, that modern quantum mechanics appears to provide for the recently postulated inexpressibility of the whole in terms of its parts. Again, that the determinism which is associated with Newtonian philosophy is now being rejected in favour of a less materialistic science. In a recent book, Prof. Eddington has shown that a particle may have position or velocity, but not both; it follows, therefore, that prediction of the future is a statistical problem. Modern science tends to acknowledge the element of volition.

\section{Chemical Engineming.}

Chemical engineering education and research in Great Britain, a matter which is of exceptional importance in the post-War development of British industry, formed the subject of the inaugural lecture delivered by Prof. W. E. Gibbs at University College, London, on Dec. 3. The age has passed when coal, for example, was regarded simply as a convenient combustible or as a raw material from which gas, coke, tar, and smoke can be obtained; the chemist to-day is altering the whole basis of coal valuation. Likewise, as Prof. Gibbs pointed out, the atmosphere has become a source of ammonia and nitric acid, as well as of oxygen; wood is being transformed into a variety of products in which we can no longer recognise the original material-paper, artificial silk, plastics, lacquers, sugar, and alcohol; waste products such as casein have provided the foundation of new industries.

Whereas the pioneering work connected with the establishment of new chemical industries - new reservoirs of national power and prosperity - and the better equipment of existing industries in the face of worldcompetition has its origin in the laboratory, it must be realised that the problems and difficulties that arise in a works, and may threaten not only economic success, but also the very practicability of a manufacturing process, are entirely different from those encountered in a laboratory. The successful transformation from the experimental to the commercial scale requires not only a sound understanding of the scientific principles which are being employed in a chemical reaction, but also it demands more than casual acquaintance with the theory and practice of civil, mechanical, and electrical engineering, with the control of labour, with the financial returns, and with market conditions and requirements. Such matters properly belong to the newly developing science of chemical engineering - a distinct and separate branch of science with its own problems, its own methods, and its own opportunities.

Prof. Gibbs stated the case for the specialised training of chemical engineers very simply as follows : "An industrial chemical process is at heart a chemical reaction, but the reaction is hidden away in an elaborate arrangement of plant and machinery. The engineer can generally fathom the meaning of the machinery, but the reaction baffles him. The chemist can understand the reaction if only he can find out where it is going on. Neither understands the complete process, nor can they together grasp it completely. For there is much in an industrial chemical process which only occurs when the work of the chemist and the work of the engineer are brought together. It has become necessary, therefore, to train men who shall be able to see the process as a whole. . . This is the function of the chemical engineer."

Prof. Gibbs did not, however, disparage the work of those who, because of unusual opportunities, or as the result of long apprenticeship, have developed without specialised instruction into exceedingly able engineers; but he declared that the supply of able men from this source is, from the point of view of present needs, too slow and uncertain. He described in some detail the type of work which, in modern chemical industry, requires the co-ordinated knowledge and experience which is being made available, for example, at University College and the Imperial College of Science and Technology. The product which they aim at producing is (quoting from his predecessor, Dr. E. C. Williams) "a scientific man whose duty it is to plan the large-scale commercial operation of chemical processes, and to design and operate the plant required for the carrying out of the chemical reactions and physical changes involved."

The chemical engineer is not concerned with the original research, which is in the domain of the laboratory chemist, or with the construction of the plant, which is the business of the engineer. The chemical engineer should know when to sacrifice chemical efficiency to economic efficiency. He would of course have opportunities of original investigation in studying the peculiar problems that arise during the opera. tion of a process.

Moreover, there are many problems concerning the physical and chemical behaviour of new structural materials, and of old materials under new conditions, that await solution. We require much more information concerning, for example, heat transfer through dividing walls, the power absorbed in transporting powders through pipe lines, the production of crystals from gases and liquids, the flocculation of fogs and smokes, the adsorption of vapours, and the behaviour of colloidal substances in large quantities. It is clearly desirable that chemical employers and chemical plant manufacturers should either undertake or endow research with the view of the acquisition of fundamental data, as well as the elucidation of specific problems.

\section{University and Educational Intelligence.}

Cambridge.-Mr. A. F. R. Wollaston has been re-elected fellow and tutor of King's College. Prof. S. Chapman has been appointed Rause Ball lecturer in mathematics for the present year. Mr. A. S. Besicovitch has been appointed Cayley lecturer in mathematics. The Arnold Gerstenberg Studentship has been awarded to C. H. Waddington, Sidney Sussex College. The Raymond Horton-Smith Prize has been awarded to $H$. Gainsborough, Downing College, for his work on "So-called Lipoid Nephrosis"; proxime accessit, E. G. Holmes, Christ's College, whose subject was "Metabolism of Nervous Tissue."

The Court of the Goldsmiths' Company has resolved that "in view of the close association between the company and the metallurgical department at Cambridge, and in view of the distinguished work carried out by Mr. C. T. Heycock, F.R.S., during his tenure of the readership (from which he has just retired)," it will transfer ultimately a capital sum of $£ 10,000$ to increase the endowment of the Goldsmiths' readership in metallurgy.

A sCIENTIFIC research fellowship is being offered by Girton College, Cambridge, for research in mathematical, physical, and natural sciences, including engineering, medicine, and agriculture. The fellowship will be of the annual value of $£ 300$ and tenable for three years. Particulars are obtainable from the Secretary of the College, to whom applications should be sent on or before Feb. 1 next.

No. 3084, VoL. 122] 